\title{
Propargyl Claisen Rearrangement: Allene Synthesis and Beyond
}

\author{
David Tejedor, ${ }^{\text {a }}$ Gabriela Méndez-Abt, ${ }^{a}$ Leandro Cotos $^{\mathrm{a}}$ and Fernando García-Tellado*a \\ Received (in $X X X, X X X) X$ th $X X X X X X X X X 200 X$, Accepted $X$ th $X X X X X X X X X 200 X$ \\ DOI: $10.1039 / \mathrm{b000000x}$
}

${ }_{5}$ The propargyl Claisen rearrangement is a known protocol to gain access to functionalized allenes through the [3,3]-sigmatropic transformation of propargyl vinyl ethers. The correct use of appropriate propargyl vinyl ethers as starting materials coupled with suitable reaction conditions can aid in the development of new domino methodologies in which the allenes are valuable intermediates in route to a wide range of important classes of organic compounds.

\section{Introduction}

10 On the $100^{\text {th }}$ anniversary of the discovery of the Claisen rearrangement, ${ }^{1}$ most organic chemists would undoubtedly regard it as one of the fundamental reactions of the field. Classically, the Claisen rearrangement can be described as the [3,3]-sigmatropic transformation of an allyl vinyl ether $\mathbf{1}$ into a $\gamma, \delta$-unsaturated 15 carbonyl compound 2 (Scheme 1). Many variations of this reaction are known regarding the substitution pattern of the vinyl group or the introduction of an aryl group, heteroatoms (most commonly nitrogen or sulphur) or a propargyl group. Due to its popularity, the Claisen rearrangement has received much 20 attention, and it has been the subject of different comprehensive reviews. ${ }^{2-4}$ At best, some of these reviews have incorporated the propargyl Claisen rearrangement as a minor component, always with the aim of studying the initial step involving the acetylenic bond, and never of exploring the potential that lies beyond. ${ }^{5}$

25
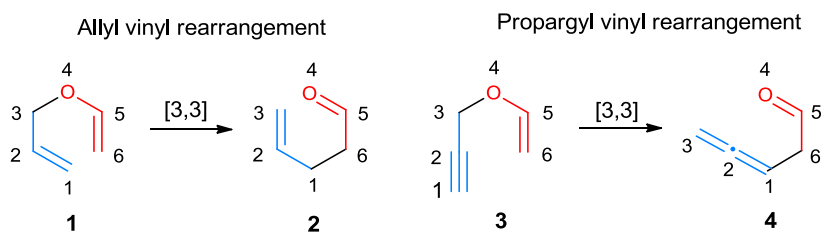

Scheme 1. Allyl vinyl rearrangement vs. propargyl vinyl rearrangement.

Since the first report by Claisen, and for the next fifty years, there was a general erroneous idea that a triple bond could not 30 participate in such rearrengements. The fact that propargyl aryl ethers did not rearrange under the studied reaction conditions in the same way that allyl aryl ethers did, led to conclude that the triple bond could not participate in the reaction for geometrical reasons. It was not until the early 1960's, that the first successful

35 attempts on the rearrangement of a propargyl aryl ether was reported. ${ }^{6}$

Consequently, the aliphatic propargylic Claisen rearrangement, which was first reported by Black and Landor in $1965{ }^{7}$ nowadays is a known protocol to gain access to functionalized 40 allenes 4 through the [3,3]-sigmatropic transformation of propargyl vinyl ethers 3 (Scheme 1). Although allenes are themselves a sought after class of organic compounds, ${ }^{8}$ they are in many cases excellent intermediates in route to other arrays of functional groups. As recent scientific literature reveals, this may 45 be particularly the case for those allenes synthesized via the aliphatic acetylenic Claisen rearrangement of appropriate starting materials. Indeed, a wide range of important classes of organic compounds have been synthesized in this way. More importantly, they are often synthesized without the need to isolate the allene 50 intermediates, via domino reactions that always begin with the Claisen rearrangement.

The aim of this tutorial review is to highlight the acetylenic version of the Claisen rearragement and to show how the correct use of appropriate propargyl vinyl ethers (or the propargyl ${ }_{55}$ alcohol precursors) and suitable reaction conditions are the key to the understanding and the development of new methodologies in synthetic organic chemistry and for the design of new domino methodologies with marked applications in the area of diversityoriented synthesis. This review does not intend to be 60 comprehensive, but rather, it will highlight pioneering and modern applications of this [3,3]-sigmatropic transformation.

The majority of the reported propargyl Claisen rearrangements require high temperatures. As a result, they have been usually conducted in high boiling solvents. To transform this reaction 65 into a more synthetically useful procedure, two key milestones in this field have been reported in the last decade: the transition metal catalyzed rearrangement and the microwave induced rearrangement of the propargyl vinyl ethers. The original work of Toste and co-workers deserves a special mention since it became 70 the first example of a catalytic version of the Claisen rearrangement of propargyl vinyl ethers conducted at room temperature (Scheme 2). ${ }^{9}$ Although the majority of the examples covered in this review are conducted at high temperatures, it will be observed that there is a definite trend in the recent literature 75 for using more friendly reaction conditions with the use of metal catalysis or the replacement of conventional heating with laboratory microwave equipment.

It must be pointed out that although over the years different names have been used to refer to this process (i.e. acetylenic ${ }_{80}$ Claisen rearrangement, propargyl Claisen rearrangement or 


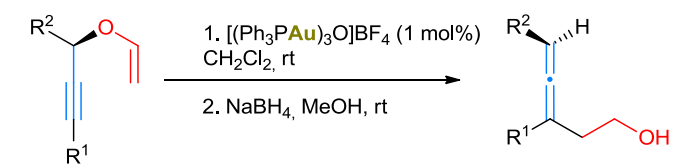

(S)-3a $\mathrm{R}^{1}=\mathrm{H}, \mathrm{R}^{2}=\mathrm{Ph} ; 92 \%$ ee

(R)-3b $\mathrm{R}^{1}=-\left(\mathrm{CH}_{2}\right)_{3} \mathrm{Ph}, \mathrm{R}^{2}=\mathrm{Me} ; 79 \%$ ee

(R)-3c R $\mathrm{R}^{1}=\mathrm{SiMe}_{3}, \mathrm{R}^{2}=\mathrm{Ph} ; 92 \%$ ee

(S) $-4 \mathrm{a} 78 \%, 88 \%$ ee (R)-4b $84 \%, 77 \%$ ee (R)-4c $98 \%, 92 \%$ ee

Scheme 2. Au(I)-catalysed propargyl Claisen rearrangement.

Saucy-Marbet rearrangement), in this review the term propargyl Claisen rearrangement will be used regardless of the substitution 5 pattern present in the vinyl functionality. Finally, the rearrangement of propargyl aryl ethers or the aza- and thioClaisen rearrangements will not be covered as there are only limited examples that do not significantly add to the conceptual aims of this review. Examples of such rearrangements can be 10 extracted from other comprehensive reviews on the Claisen rearrangement. $^{2-4}$

\section{Propargyl vinyl (aryl) ethers}

The interest of the propargyl Claisen rearrangement justifies the importance of the availability of the starting materials. Thus, 15 propargyl vinyl ethers (PVEs) constitute a privileged group of small size, structurally simple, readily available, and densely functionalized scaffolds. The key to the chemical reactivity encoded in these structures is the [3,3] propargylic sigmatropic rearrangement shown in Scheme 1, but nevertheless, there exists 20 also the possibility to separately take advantage of each of the different functionalities. With regard to the propargyl Claisen rearrangement, as in any other [3,3]-sigmatropic rearrangement, it takes place under thermodynamic control. This reaction is by all means irreversible toward the formation of the carbonyl ${ }_{25}$ compounds as the retro-Claisen rearrangement of allenic substrates has never been observed.

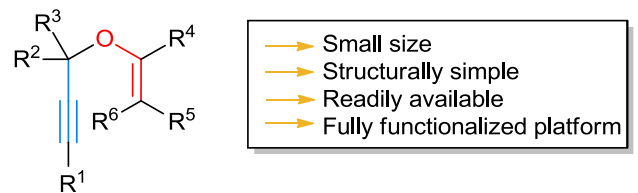

Figure 1. Propargyl vinyl ethers (PVEs): versatile synthetic platforms.

Another important aspect that will be observed throughout this review is that the degree and pattern of substitution in the PVEs will have a great impact on the outcome of the reactions. Although a systematic study on the influence of the different 35 susbstituents in propargylic substrates has not been carried out, a recurrent observation made since the pioneer work of Black and Landor in 1965 is that increased substitution in the PVE leads to a more efficient rearrangement at lower temperatures. As it has already been pointed out, this shows that steric hindrance in the 40 transition state is not the most relevant factor in terms of energy dependency. ${ }^{7}$ On the other hand, inductive or mesomeric effects of electron-withdrawing or electron-donating substituents located at different positions of the carbon skeleton are expected to be similar to those observed for the better-studied Claisen 45 rearrangement of allyl vinyl ethers. ${ }^{2}$
The pace by which the propargyl Claisen rearrangement has progressed has been largely dictated by the availability of the PVEs, or even more importantly, by the availability of methodologies used to construct them. With regard to this fact, 50 we now present the main advances in the synthesis of PVEs from a historical point of view (Schemes 3-7), and appropriate examples of how different research lines have taken advantage of the PVEs and the allene products derived from them.

\section{Synthesis from propargyl alcohol and aldehydes}

55
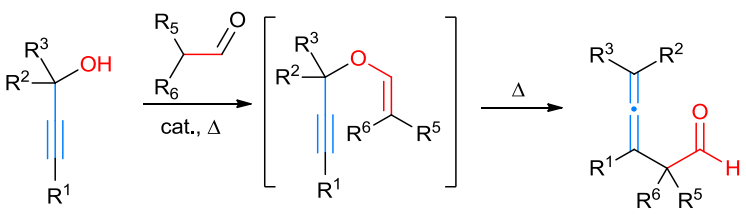

Scheme 3. Synthesis from propargyl alcohol and aldehydes.

In their first report dealing with PVEs, Black and Landor, concluded that this rearrangement provided a new general method ${ }_{60}$ for the synthesis of allenic aldehydes. First, the desired starting materials were prepared following their own previously described methodology from propargyl alcohols and aldehydes with the aid of boron trichloride and trimethylamine. Thus, the PVEs (or the $\alpha$-chloroalkyl ether precursors for the less substituted examples) 65 were heated at temperatures ranging from $140-250{ }^{\circ} \mathrm{C}$ to give the corresponding allenic aldehydes (Scheme 3$)^{7}$ This work served to determine that, although less favourable, propargylic systems could be accomodated into the Claisen rearrangement with the use of higher temperatures.

70 More recently, this procedure for the synthesis of PVEs has been used to prepare allenes via the propargyl Claisen rearrangement with slight changes in the experimental protocol. For instance, Tsuno and co-workers prepared an allenic aldehyde in multigram quantities from 2-methyl-4-phenyl-3-butyn-2-ol,

75 and isobutyraldehyde in the presence of a catalytic amount of $p$ toluenesulfonic acid. ${ }^{10}$ In addition, a series of allenic aldehydes were prepared by Potáček et al. using $\mathrm{HCl}$ and pyridine for the synthesis of the PVEs instead of the boron trichloride/ trimethylamine system. ${ }^{11}$

${ }_{80}$ Although in general, there are few examples of the use of aldehydes in the synthesis of PVEs, it appears to be an appealing procedure when the desired allenic aldehyde is fully substituted in the $\alpha$-position to the carbonyl group $\left(\mathrm{R}^{5}\right.$ and $\left.\mathrm{R}^{6} \neq \mathrm{H}\right)$.

\section{Synthesis from propargyl alcohol and isopropenyl ethers}

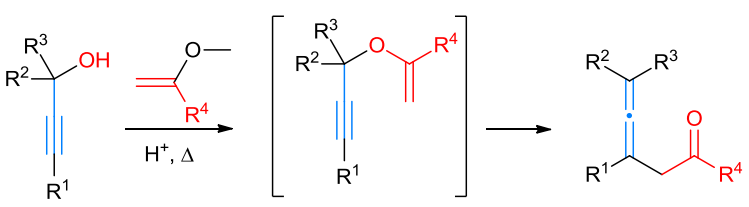

Scheme 4. Synthesis from propargyl alcohol and isopropenyl ethers.

The acid-catalysed reaction of isopropenyl ethers with ${ }_{90}$ acetylenic carbinols to give $\beta$-ketoallenes in high yields is the so called Saucy-Marbet rearrangement (Scheme 4) $\left(\mathrm{R}^{4}=\mathrm{Me}\right){ }^{12}$ The 
main consequence from the employment of the isopropenyl ether is that a PVE is formed with a substituted vinyl functionality which, upon rearrangement, produces an allenic ketone instead of an allenic aldehyde. Furthemore, upon treatment with bases, these 5 allenes readily undergo isomerization to conjugated dienones, leading to important intermediates in the production of flavors, fragances, pharmaceuticals and other fine chemicals. Since the reaction is known to take place under acid catalysis in volatile organic solvents, different research approaches are beeing 10 envisaged to generate a greener and more sustainable process for industrial applications. ${ }^{13}$

\section{Synthesis from propargyl alcohols and orthoesters}

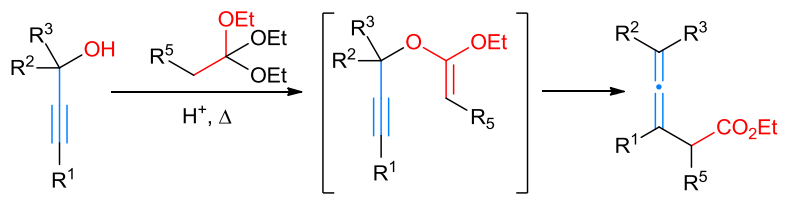

Scheme 5. Synthesis from propargyl alcohols and orthoesters.

Shortly after the disclosure of a version of the Claisen rearrangement by Johnson and co-workers involving allylic 20 alcohols and excess ethyl orthoacetate in the presence of a trace amount of a weak acid (Johnson-Claisen rearrangement), ${ }^{14}$ a similar report by Crandall and Tindell described the synthesis of $\beta$-allenic esters from propargyl alcohols (Scheme 5). ${ }^{15}$ Without a doubt, these two reports constitute a landmark in the synthesis of 25 functionalized allenes through the [3,3]-sigmatropic transformation of readily available starting materials. The new methodology called for the heating of appropriate propargyl alcohols, 4-7 equivalents of triethyl orthoacetate and a catalytic amount of propionic acid with removal of ethanol by distillation.

30 Furthermore, the methodology benefits from an increased tolerance in the substitution pattern of the starting materials and a higher stability (reduced reactivity) of the allenic esters with respect to the allenic aldehydes which translates in higher yields of the products.

35 In general, the Johnson orthoester Claisen rearrangement of substituted propargylic alcohols is therefore a robust and reliable methodology to construct $\beta$-allenic esters, or more complex compounds that can be accessed from these useful scaffolds, with high levels of enantiomeric excess. In this case, the PVEs are 40 only convenient intermediates of the complete transformation because they can never be isolated under the reaction conditions required for their formation.

\section{Synthesis from propargyl alcohols and ethyl vinyl ether}

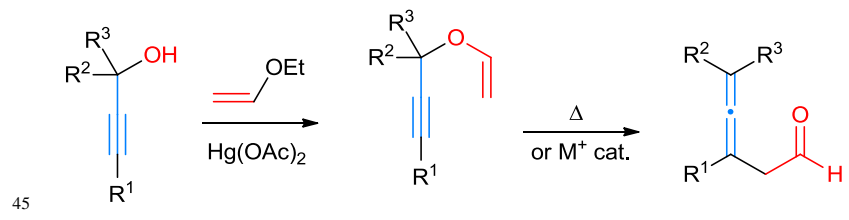

Scheme 6. Synthesis from propargyl alcohols and ethyl vinyl ether.

In certain occasions, a line of research may require the use of an isolable PVE possessing the unsubstituted vinyl functionality ${ }_{50}\left(\mathrm{R}^{4}=\mathrm{R}^{5}=\mathrm{R}^{6}=\mathrm{H}\right.$, Figure 1$)$. In some earlier studies, the plain propargyl vinyl ether (additionally, $\mathrm{R}^{1}=\mathrm{R}^{2}=\mathrm{R}^{3}=\mathrm{H}$ ) was prepared according to the method of Black and Landor, ${ }^{7}$ although a different approach was also reported employing 2-propyn-1-ol and (trimethylsilyl)oxirane. ${ }^{16}$ On the other hand, in the majority 55 of occasions $\mathrm{R}^{1}$ and $\mathrm{R}^{2}$ or $\mathrm{R}^{3} \neq \mathrm{H}$, and the method of choice to introduce the vinyl functionality has been the use of ethyl vinyl ether and propargyl alcohols in the presence of mercury (II) acetate (Scheme 6). ${ }^{17,18}$ The [3,3]-sigmatropic rearrangement of these substrates gains therefore access to allenic aldehydes free of ${ }_{60}$ substituents in the $\alpha$-position which can be engaged in further transformations.

Synthesis from propargyl alcohols and conjugated alkynoates

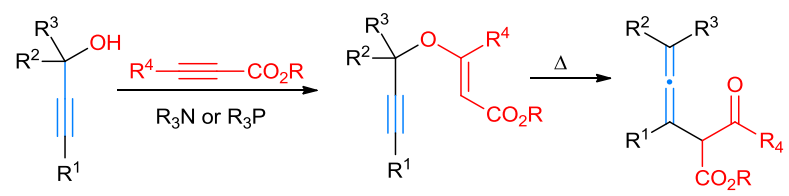

${ }_{65}$ Scheme 7. Synthesis from propargyl alcohols and conjugated alkynoates.

Isolable PVEs possessing a substituted vinyl functionality are readily available from the trialkylamine or trialkylphosphine catalysed addition of propargylic alcohols to conjugated 70 alkynoates (Scheme 7), ${ }^{19-21}$ although obviously, $\mathrm{R}^{6}=\mathrm{H}$ (Figure 1). It must be added at this point that PVEs with this type of vinyl substitution pattern can also be accessed directly from alkyl propiolates and aldehydes in a very straightforward manner if $\mathrm{R}^{1}$ $=\mathrm{CO}_{2} \mathrm{R}^{22}$

75 When using a terminal alkyl propiolate, triethylamine seems to be the most convenient catalyst for the reaction, and the PVEs are synthesised in high yields and short periods of time at room temperature $\left(\mathrm{R}^{4}=\mathrm{H}\right.$, Figure 1$)$. In this case, a limitation of the reaction is that most tertiary alcohols do not afford the desired 80 products in synthetically useful yields. Only tertiary alcohols having an electron withdrawing group are capable of participating as appropriate starting materials. When using internal alkynoates, trialkylphosphines must be used because the amine counterparts are not sufficiently nucleophilic to trigger the reaction.

85 As it will be seen in some of the remaining parts of the review, this methodology is one of the most frequently used in the modern synthesis of PVEs. The [3,3]-sigmatropic rearrangement of this substrates affords allenic aldehydes or ketones, with an ester group in the $\alpha$-position, that are often transformed into more 90 complex structures.

\section{Miscellaneous methods}

The synthesis of PVEs is not limited to the methodologies shown in Schemes 3-7. Other methodologies have been used to prepare specific molecules or families of compounds that contain 95 this $\mathrm{C}_{2}-\mathrm{O}-\mathrm{C}_{3}$ motive with or without the intention of performing the corresponding rearrangement. Nevertheless, the methodologies shown in Scheme $8(\mathrm{a}-\mathrm{g})$ are representative examples of different types of reactivities directed to isolate PVEs.

100 The landmark synthesis of azadirachtin complex natural 
a)

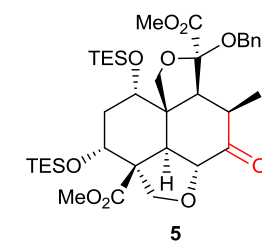

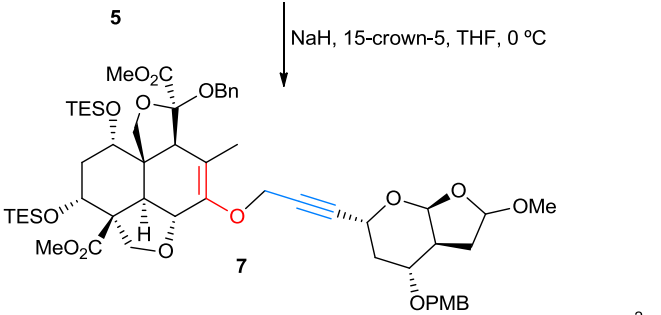

b)<smiles>O=C(O)c1c[nH]c2ccncc12</smiles>

1. N-chlorosuccinimide $\underset{\text { 2. } \mathrm{Cl}_{3} \mathrm{CCO}_{2} \mathrm{H}}{\stackrel{\text { 1,4-dimethylpiperazine }}{\longrightarrow}}$<smiles>[R]C#CCO</smiles>

PMB

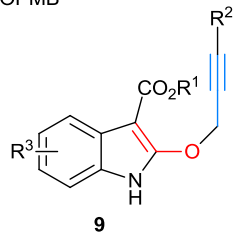

c)<smiles>[Z]C(=C)C1(O)C(=O)N([R])c2ccc([R])cc21</smiles>

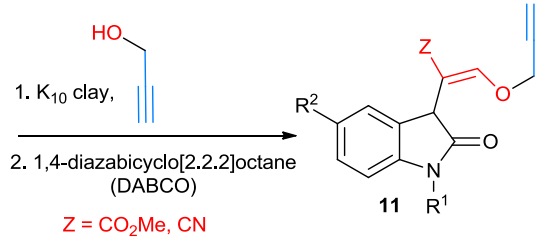

d)<smiles>[R]C1C(=O)C(Cl)=C(Cl)C12OCCO2</smiles>
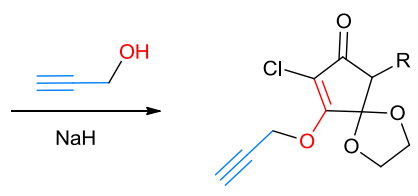

13

e)<smiles>Cn1cc(O)c(=O)n([N+](=O)[O-])c1=O</smiles>

14<smiles>C=COCC#C[SiH]CCC</smiles>

16
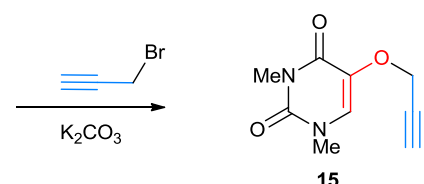

15

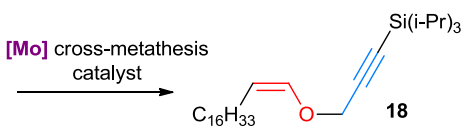

17

g)

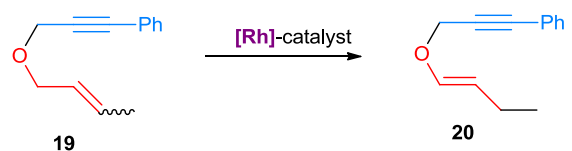

Scheme 8. Miscellaneous synthesis of propargyl vinyl ethers.

product by Ley's group called for the synthesis of $\mathrm{n}$ intermediate 5 (Scheme 8, a). Despite the observed mixtures of $O$ - and $C$ alkylation products in experiments with simplified models of fragments 5 and $\mathbf{6}$, the real system produced exclusively the desired $O$-alkylated product when the experimental protocol was carefully designed. ${ }^{23}$
10 In a recent report dealing with the search for a catalytic enantioselective Claisen rearrangement of alkynyl vinyl ethers, propargyl-substituted indoles $\mathbf{8}$ were treated with $\mathrm{N}$ chlorosuccinimide followed by substituted propargyl alcohols in the presence of an acid catalyst to afford a series of compounds 9 15 that contain the triple and the double bonds with the correct connectivity (Scheme $8, \mathrm{~b}){ }^{24}$

Morita-Baylis-Hillman adducts of isatin derivatives $\mathbf{1 0}$ have been transformed into propargyl ethers bearing a trisubstituted vinyl moiety 11 (Scheme $8, \mathrm{c})\left(\mathrm{Z}=\mathrm{CO}_{2} \mathrm{Me}, \mathrm{CN}\right){ }^{25}$ The reaction 20 takes place by nucleophilic addition of propargyl alcohol onto the Morita-Baylis-Hillman adduct, followed by a base-promoted isomerisation of the resulting allylic intermediate. In this same report, the highly functionalised PVEs are converted into the corresponding allenes via Claisen rearrangement in 25 chlorobenzene at $135^{\circ} \mathrm{C}$ in good yields.

Another strategy employed is to use substrates possessing vinyl chlorides (or other halides) that have a tendency to participate in substitution reactions with heteroatom-nucleophiles. For example, 2,3-dichlorocyclopentenones 12 react with the 30 anion of propargyl alcohol to deliver the PVEs 13 (Scheme 8, d). ${ }^{26}$

The reactivity of the reacting partners may also be changed as evidenced by the example shown in Scheme 8, e. $^{27}$ A vinyl alcohol, such as 14, in the presence of a base can act as the 35 nucleophilic species, while a propargyl bromide can act as the electrophilic counterpart. This methodology is reminiscent of the typical synthesis of propargyl aryl ethers. Furthermore, the [3,3]sigmatropic rearrangement of substrate $\mathbf{1 5}$ affords an allene intermediate that gives 5- or 6-membered cyclisation products 40 through a domino process.

Finally, reactions f) and $\mathrm{g}$ ) in Scheme 8 show two methods that have great potential applications. A novel approach to PVEs containing a substituted vinyl group has been recently reported (Scheme 8, f). Since the introduction of the plain vinyl group is 45 well established (from propargyl alcohols and ethyl vinyl ether, see previous section), the desired vinyl group can be exchanged through a cross-metathesis reaction of an appropriate alkene. ${ }^{28}$ On the other hand, the selective Rh-catalysed olefin isomerisation of 1,6-enynes instead of the better studied intramolecular 50 cycloisomerisation provides PVEs (Scheme $8, \mathrm{~g}$ ). ${ }^{29}$ It is anticipated that these methodologies will be more regularly used in the future with applications that include a [3,3]-sigmatropic rearrangement.

It must also be added that there are other miscellaneous 55 methodologies where, as in the case of the Johnson orthoester Claisen rearrangement, the PVEs are only reactive intermediates in way to the synthesis of allenic species. A good example may be the work done by Hsung and co-workers regarding the stereoselective synthesis of allenic amides from the acid60 catalysed reaction of chiral ynamides $(R)-\mathbf{2 1}$ and propargyl alcohols (Scheme 9). ${ }^{30}$ In the typical experimental conditions, the starting materials were heated at $100{ }^{\circ} \mathrm{C}$ in sealed tubes for $24-48$ $\mathrm{h}$, where the PVEs were formed in situ and continued with the rearrangement to the corresponding allenes $\mathbf{2 2}$ and $\mathbf{2 3}$.

\section{${ }_{65}$ Allene synthesis and beyond}




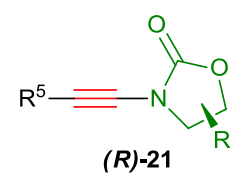

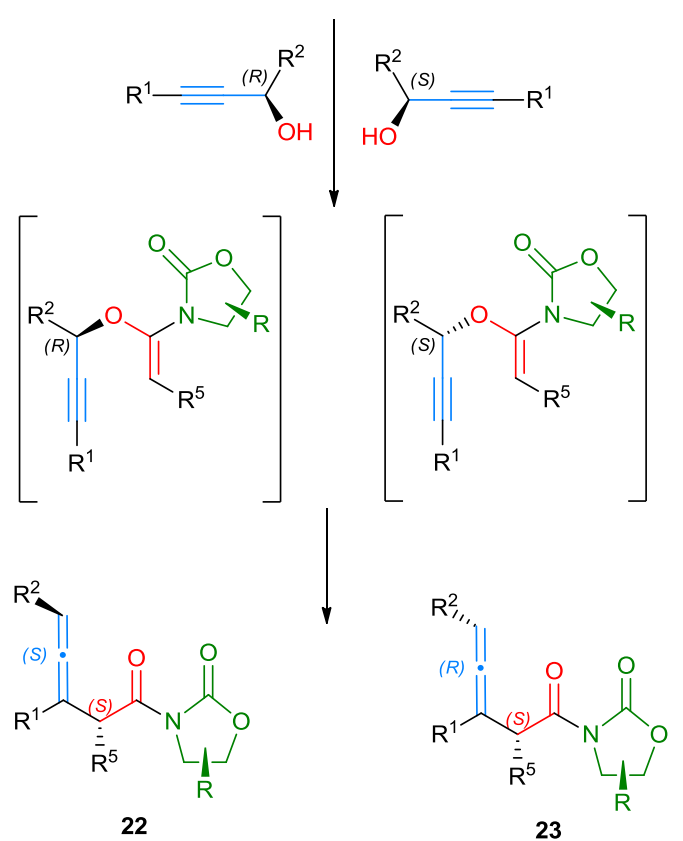

Scheme 9. Stereoselective propargyl Claisen rearrangement using chiral ynamides.

Although allenes are themselves a sought after class of organic 5 compounds, they are in many cases excellent intermediates in route to other arrays of functional groups. In this section we will see how different strategies utilise the propargyl Claisen methodologies to gain access to more complex structures through functionalised allenes synthesised from PVEs.

\section{${ }_{10}$ Propargyl vinyl ethers as reactive intermediates}

In many instances, the Johnson orthoester Claisen rearrangement of substituted propargylic alcohols is therefore the starting point for the development of a wide range of synthetic methodologies, being the PVE only a convenient intermediate of 15 the reaction. For example, the group of Panek developed a suitable procedure for the synthesis of highly enantioenriched allenylsilane 25 from chiral propargylic alcohol 24, which was further converted into functionalised alkynes (26, 27 and 30), 4,5dihyrooxazines 28, 4,5-dihydropyrroles $\mathbf{2 9}$ and fused ring 20 systems containing 1,2,3-triazoles (31 and 32, Scheme 10). ${ }^{31,32}$ It is worth mentioning that the key formation of the allenylsilanes were performed in refluxing xylenes with a catalytic amount of propionic acid in a $25 \mathrm{mmol}$ scale. (R)-24 afforded $\left(\mathrm{S}_{\mathrm{a}}\right)-\mathbf{2 5}$ in 79\% yield and $98 \%$ ee while $(\mathrm{S})-\mathbf{2 4}$ afforded $\left(\mathrm{R}_{\mathrm{a}}\right)-\mathbf{2 5}$ in $81 \%$ 25 yield and $98 \%$ ee.

Trost et al. have developed a synthesis of 1,3-dienes via a ruthenium-catalysed reaction of allenes and activated olefins (Scheme 11). ${ }^{33}$ To study the scope of the allenic component they utilised the propargyl orthoester Claisen rearrangement arguing 30 that it is the most versatile and atom economic method for the preparation of allenic ester derivatives containing a full range of substitution patterns in the molecule. Interestingly, a set of tertiary allenic amides were also prepared with a modified procedure that employs dimethylacetamide acetals instead of 35 triethyl orthoacetate. ${ }^{34}$ The work studies in detail the reactivity of mono-, di-, tri- and tetrasubstituted allenes towards activated olefins.

In another recent study, $(2 E, 4 E)$-4-carbinol alkadienoates 38 have been synthesised stereoselectively in a two-step procedure 40 from propargylic alcohols through a Claisen rearrangement aldol reaction sequence (Scheme 12). ${ }^{35}$ The $\beta$-allenyl ester intermediates $\mathbf{3 7}$ were functionalized through trapping of the allenyl enolate with a carbon electrophile. Confirming that the

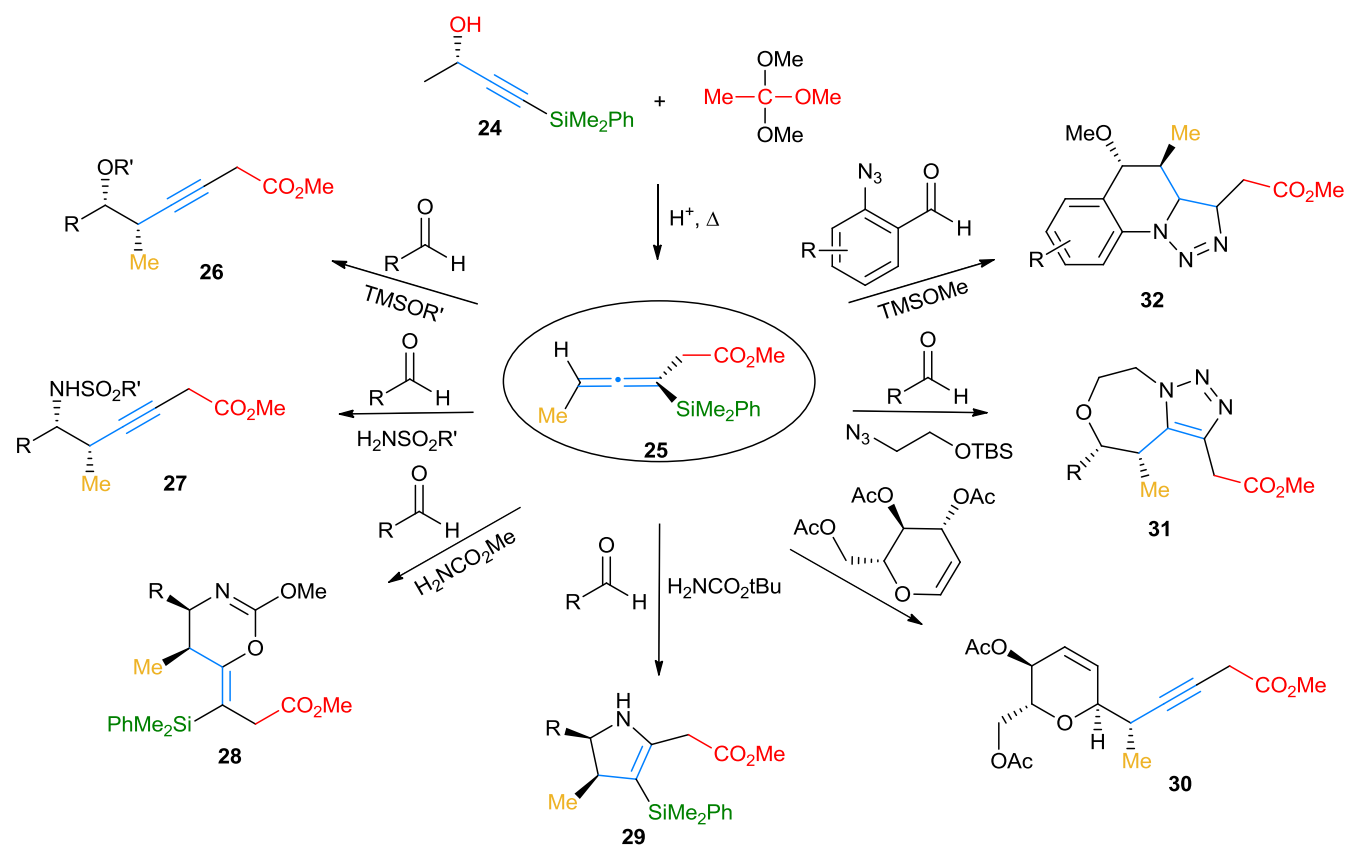

Scheme 10. Synthesis and applications of highly enantioenriched allenylsilane $\mathbf{2 5}$. 


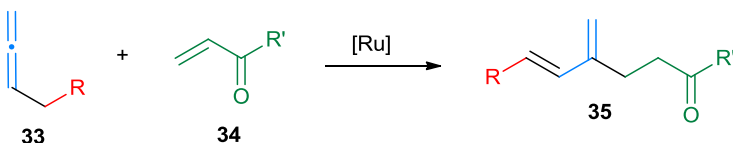

33

34

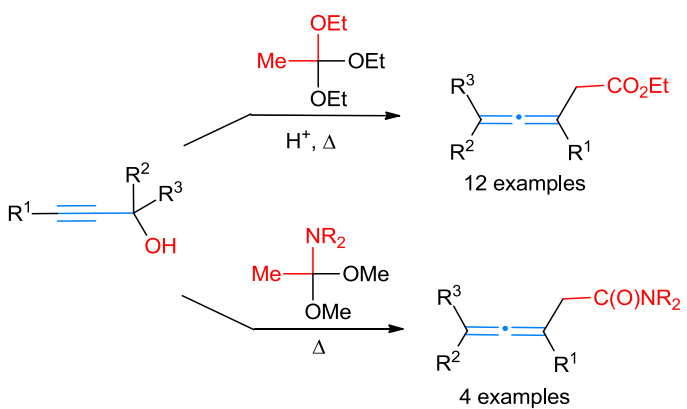

Scheme 11. Ruthenium-catalysed two-component formation of 1,3dienes. Synthesis of starting allenic compounds.

rearrangement is a robust methodology, the $\beta$-allenyl esters were 5 prepared in up to $70 \mathrm{mmol}$ scale.
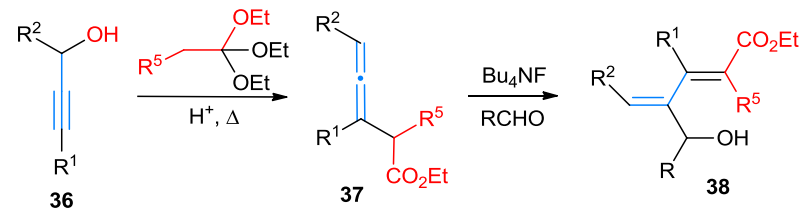

Scheme 12. Propargyl Claisen rearrangement - aldol reaction sequence.

10 The group of Ma et al. has also been particularly active in the field of allenes. In many occasions, they have found the ortho Claisen rearrangement to be especially useful in the preparation of desired intermediates. Allenols $\mathbf{3 9}$ have been converted into lactones 40 and $\mathbf{4 1}$ through highly stereoselective 15 iodolactonization, ${ }^{36}$ tetrahydrofurans $\mathbf{4 2}$ and $\mathbf{4 3}$ through highly regio- and stereoselective cyclic iodoetherification, ${ }^{37}$ or directly into compounds $\mathbf{4 4}$ through a $\mathrm{PtCl}_{4}$-catalyzed cyclization reaction in the presence of indoles ${ }^{38}$ (Scheme 13).

Alkynyl halides have also been used as functionalized starting 20 units to synthesise valuable allenyl halides via the propargyl orthoester Claisen rearrangement. For example, Hsung and col. have studied the stereospecific conversion of alkynyl halides $\mathbf{4 5}$ into allenyl bromides or chlorides $\mathbf{4 6}$ and their subsequent coupling with aldehydes with transfer of chirality (Scheme 14). ${ }^{39}$

${ }_{25}$ With regard to the transformation $\mathbf{4 5} \rightarrow \mathbf{4 6}$, the optimization of reaction conditions established that alkynyl bromides were more effective than the corresponding chlorides and iodides, while the reactions were conducted in toluene at $100{ }^{\circ} \mathrm{C}$ with $\mathrm{AcOH}$ as the catalyst. In another attractive application, alkynyl bromide 48 was 30 transformed into cumulene $\mathbf{5 0}$ through a rearrangement hydrogen bromide elimination sequence (Scheme 15). ${ }^{40}$

The field of natural product synthesis has also witnessed the use of the Johnson orthoester Claisen rearrangement of acetylenic compounds. For example, evidencing that this is an 35 straightforward methodology, propargyl alcohol and triethyl orthopropionate have been converted to an allenic alcohol in essentially quantitative yield in a multigram scale as the first step toward the synthesis of Nuphar alkaloids $\mathbf{5 1}$ and $\mathbf{5 2}$ (Scheme 16). ${ }^{41}$

40 A more elaborated propargylic alcohol $\mathbf{5 3}$ containing two

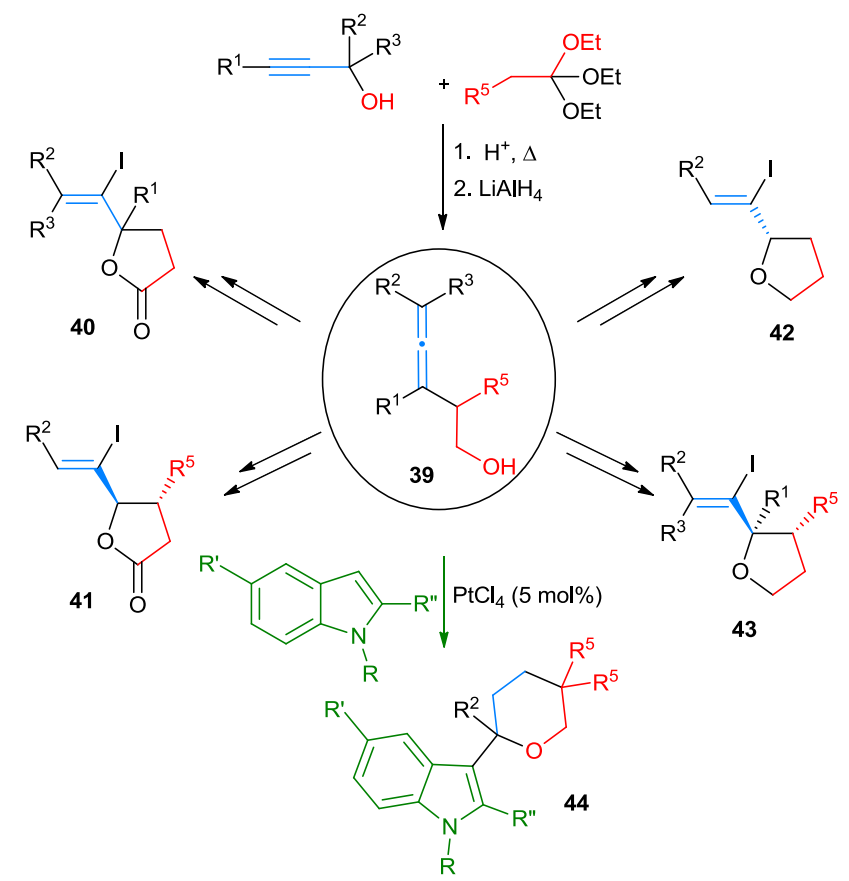

Scheme 13. Synthesis and applications of functionalised allenols 39.

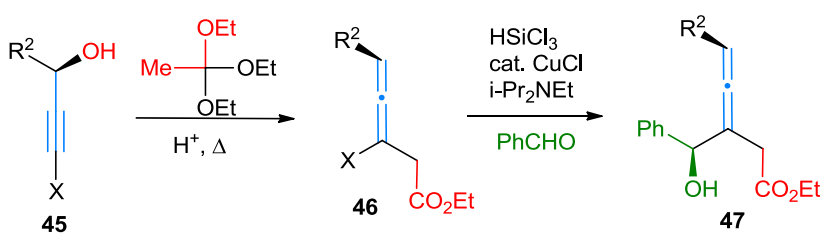

${ }_{45}$ Scheme 14. Synthesis and reactivity of enantiomerically enriched allenyl halides.

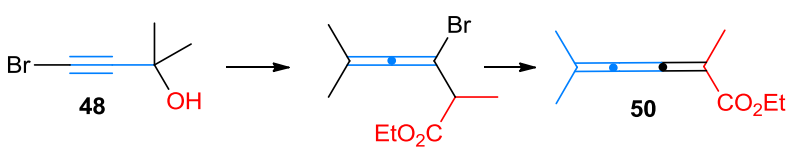

Scheme 15. Two-step synthesis of cumulenes.

50

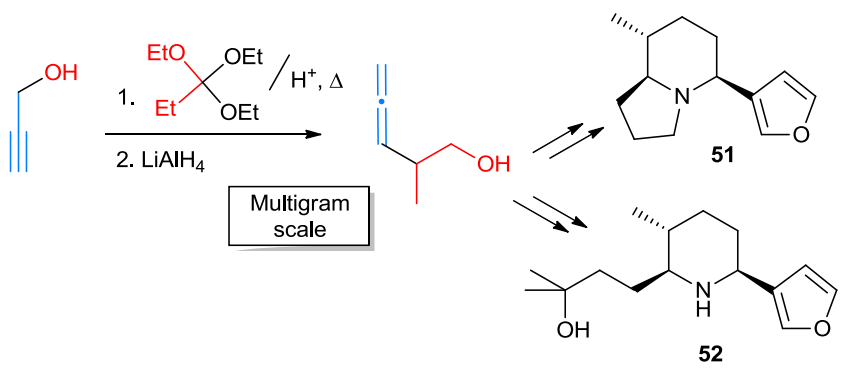

Scheme 16. Allenic alcohol in route to alkaloids $\mathbf{5 1}$ and $\mathbf{5 2}$.

protected hydroxyl groups has also been subjected to the $[3,3]$ 55 sigmatropic transformation as one of the key steps during the synthesis of Macrolactin A 56 (Scheme 17). ${ }^{42}$ The authors explain that some experimentation was required to improve the yield of allene $\mathbf{5 4}$, with the best conditions being, $140{ }^{\circ} \mathrm{C}$ in the 
presence of $10 \%$ of propionic acid during $8 \mathrm{~h}$, removing ethanol in vacuo and re-adding ethyl orthoacetate/propionic acid every 2 h. In this manner, $\mathbf{5 4}$ was found to be pure enough to be engaged in the alumina-mediated isomerization reaction to afford a 5 conjugated diene $\mathbf{5 5}$ with good stereoselectivity in favour of the desired product $(9: 1(2 E, 4 Z) /(2 E, 4 E)$ mixture). Notice that the original propargylic alcohol is easily transformed into a diene with an additional functionality (ester group) that in turn will gain access to a chiral hydroxyl group.

10

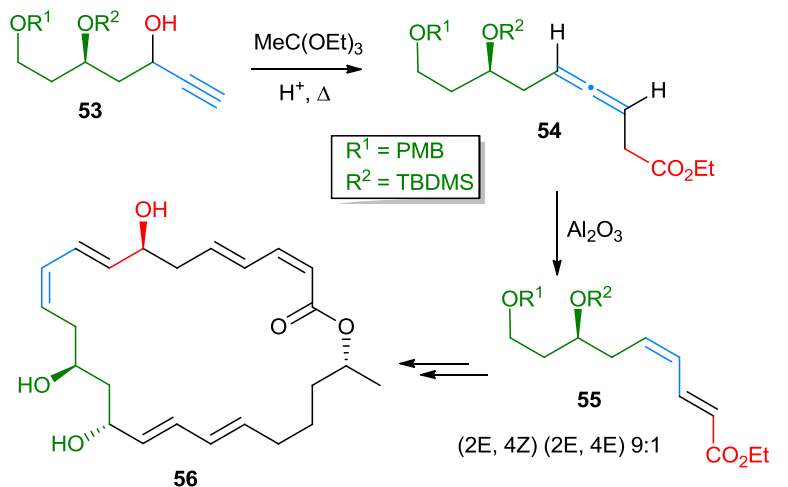

Scheme 17. Johnson orthoester Claisen rearrangement - allene isomerization in the synthesis of Macrolactin A.

In a different study, an elegant stereocontrolled total synthesis 15 of clavepictine A $\mathbf{6 3}$ and clavepictine B $\mathbf{6 4}$ was accomplished in which a key step was a rare diastereoselective silver(I)-promoted cyclisation of $\delta$-amino allenes $(\mathbf{5 9} \rightarrow \mathbf{6 0}$ Scheme 18$) .{ }^{43}$ In a first-<smiles>[R10][C@@H]1CC[C@H](CCC[C@H](O)C#C)N([Y10]([H])([H])[H])[C@@H]1C</smiles>

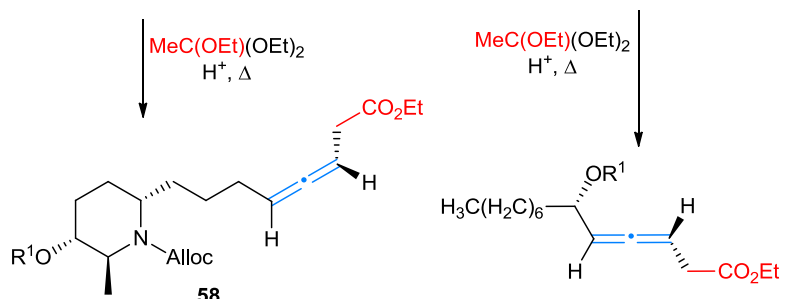

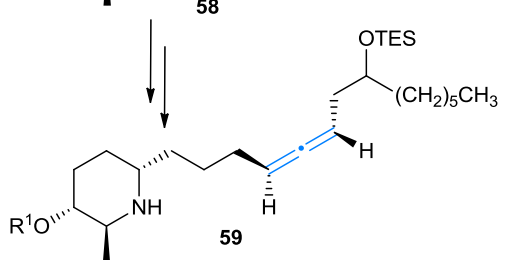

62

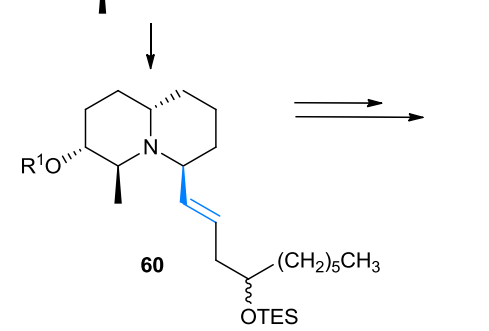<smiles>[R9][C@H]1CC[C@H]2CCCC(/C=C/C=C/C)N2[C@H]1C</smiles>

$63 \mathrm{R}=\mathrm{Ac}$, clavepictine $\mathrm{A}$ $64 \mathrm{R}=\mathrm{H}$, clavepictine $B$

20 Scheme 18. Claisen rearrangement and cyclization of $\delta$-aminoallenes in the synthesis of clavepictines A and B. Alloc = allyloxycarbonyl.

generation approach, the required allene $\mathbf{5 8}$ bearing a strategically placed piperidine ring was efficiently synthesised from a somewhat complex enantiopure propargyl alcohol $\mathbf{5 7}$ in a 25 diastereoselective manner using the standard reaction conditions in $83 \%$ yield. In a second-generation approach, seeking to reduce the overall number of steps, a propargyl alcohol $\mathbf{6 1}$ bearing a silylated protecting group but with the absence of the piperidine ring was converted into the allenic ester 62 with excellent 30 diastereocontrol in $71 \%$ yield $(1.0 \mathrm{~g}$ scale). As in the previous approach, a key diastereoselective cyclisation of a $\delta$-amino allene eventually lead to the synthesis of both clavepictine A and B.

Finally, an impressive example of domino reactions that include the selective rhodium-catalysed olefin isomerisation of 35 1,6-enynes has been recently reported (see Scheme 8 , g). The careful design of the starting 1,6-enyne (synthesised in two steps from commercially available compounds) places all the desired functionalities at strategically correct positions so that a set of rhodium catalysed reactions take place in a controlled manner 40 (Scheme 19). ${ }^{44}$ Thus, 1,6-dienyne $\mathbf{6 5}$ isomerises to PVE 66 before rearranging to the allenic aldehyde $67\left(40-80{ }^{\circ} \mathrm{C}\right)$. When secondary propargyl ethers are formed $\left(R^{2}=H\right)$ and $R^{3}$ contains a methylene group, substituted 1,4-dihydronaphthalenes $\mathbf{6 8}$ form as mixtures of diastereomers through an enallene 45 cycloisomerisation. On the other hand, when tertiary propargyl ethers are formed $\left(R^{2}=R^{3} \neq H\right)$, allenic aldehyde 67 suffers a carbonyl migration reaction followed by a cyclisation reaction to afford substituted 1,2-dihydronaphthalenes 70. If more elevated temperatures and prolonged reaction times are used, naphthalenes 50 $\mathbf{7 2}$ are formed through a carbonyl ene reaction of product $\mathbf{7 0}$.<smiles>[R]C#CC([R])([R])OCC(=C)c1ccccc1C=C</smiles><smiles>[R]C=CC1=C(C)C(C)(O)c2ccccc2C1C</smiles>

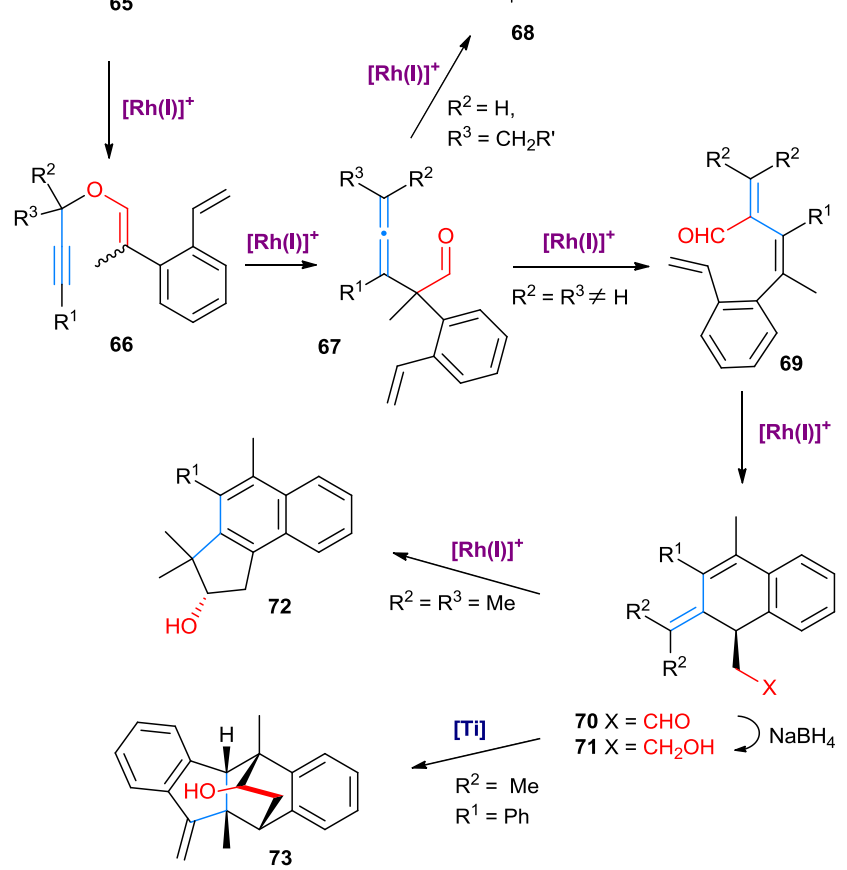

Scheme 19. Rhodium-catalysed domino reactions of 1,6-dienynes. 
Interestingly, the product formation of $\mathbf{6 8 ,} 70$ and 72 from 1,6dienyne $\mathbf{6 5}$ are selective one-pot syntheses that take place through domino processes just by changing the reaction conditions or the nature of the substituents. Additionally, if chiral bisphosphine 5 ligands are used in combination with the cationic rhodium catalyst, products 70-72 can be obtained with moderate to good enantioselectivities. Ultimately, pentacyclic product 73 can be obtained from $\mathbf{7 0}$ by the coupling of two domino processes which includes a new $\mathrm{TiCl}_{4}$ mediated transformation.

\section{Propargyl vinyl ethers as suitable platforms for domino chemistry.}

When the PVEs can be isolated, synthetic strategies may be designed so that the propargyl Claisen rearrangement is the first 15 step of a domino process, and the corresponding allenes are only reaction intermediates. For example, Grissom and co-workers designed tandem enyne allene-radical cyclisation processes by strategically placing an aromatic ring into PVEs bearing an additional alkyne functionality (Scheme 20). ${ }^{45}$ In the first case, 20 the aromatic ring is directly bonded to the alkyne which participates in the [3,3]- sigmatropic rearrangement. Thus, PVE 74 preferentially delivered allene $\mathbf{7 5}$ only as a reactive intermediate. This was followed by an enyne allene cyclisation to form biradical 76 (Myers cyclisation) and a hydrogen abstraction 25 from 1,4-cyclohexadiene to form the disubstituted naphthalene $\mathbf{7 7}$ as the major product. Furthermore, a more elaborated PVE 78 bearing the alkyne-functionalised aromatic ring at the propargylic position delivered the tricyclic product $\mathbf{7 9}$ as a mixture of diastereomers through a domino process that included an 30 additional cyclisation reaction. Hence, the overall process entailed a [3,3]- sigmatropic rearrangement - Myers cyclisation 5-exo radical cyclisation - hydrogen abstraction in chlorobenzene at $150{ }^{\circ} \mathrm{C}$

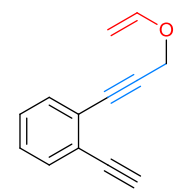

74 $\mid \begin{aligned} & {[3,3]-\text { sigmatropic }} \\ & \text { rearrangement }\end{aligned}$

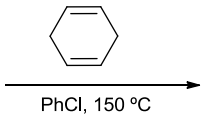<smiles>C#Cc1ccccc1C(=C)CO</smiles>

75

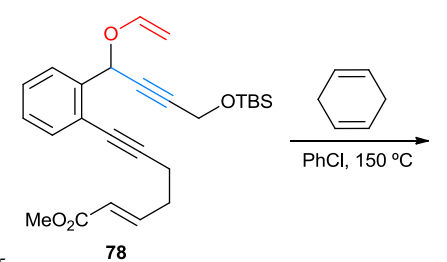

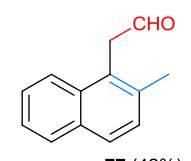

$77(42 \%)$<smiles>[3H]</smiles>
Hydrogen
abstraction abstraction

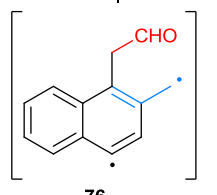

76

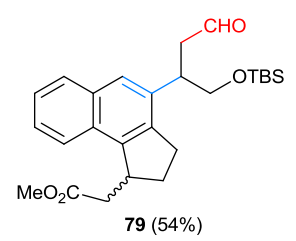

Scheme 20. An example of enyne-allene radical cyclisation.

Metal-catalysed domino processes. Gold catalysis has increased the synthetic potential of this chemistry allowing it to be performed under much milder reaction conditions and oriented to 40 more structural diversity. Scheme 2 already showed how Toste and co-workers were able to carry out the [3,3]-sigmatropic transformation at room temperature with the gold (I) complex $\left[\left(\mathrm{Ph}_{3} \mathrm{PAu}\right)_{3} \mathrm{O}\right] \mathrm{BF}_{4}$. As a general reactivity principle, in the presence of a carbophilic metal catalyst (e.g., gold), PVEs 45 rearrange into the intermediate oxonium derivatives $\mathbf{8 0}$, which in turn can afford different products as a function of the reaction conditions (Scheme 21). In the absence of an external nucleophile, the 5-exo-dig cyclization is the most favoured reaction pathway affording the corresponding furan derivatives. ${ }_{50}$ The base catalysed rearrangement of the allenal internediate into the corresponding $\alpha, \beta, \gamma, \delta$-dienal requires catalyst modulation in order to avoid the otherwise favoured formation of the furan derivative. Following this reactivity guide, the same group developed a gold-cvatalysed domino methodology to construct 55 3,6-dihydro-2H-pyran-2-ol derivatives $\mathbf{8 2}$. ${ }^{46}$ The reaction entails a gold-catalysed 6-endo-trig cyclisation followed by addition of water. Interestingly, the authors also demonstrated that the Claisen/heterocyclisation proceeded with excellent diastereocontrol and chirality transfer from the PVE stereocenter 60 (Scheme 22).

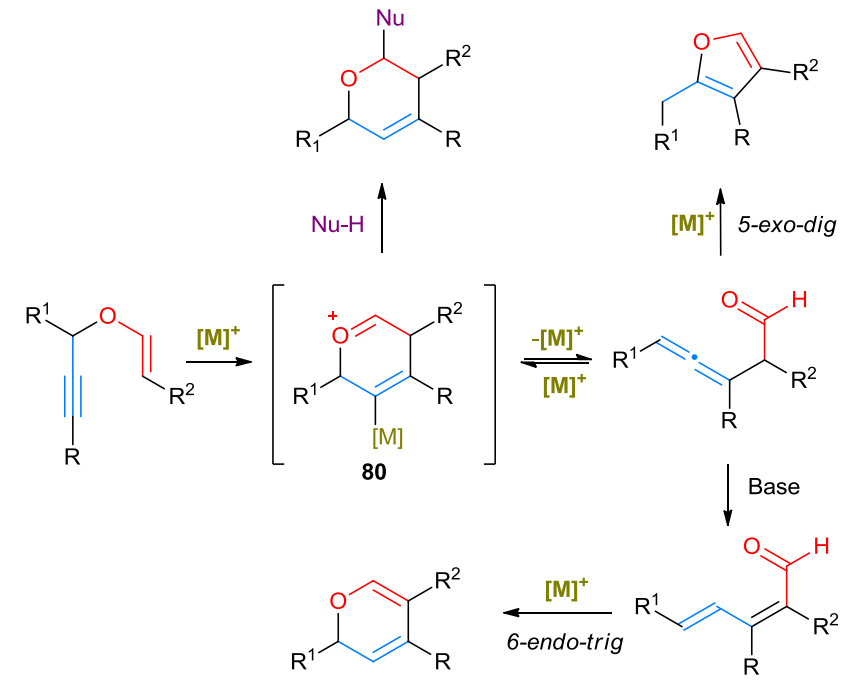

Scheme 21. Metal-catalysed rearrangements of PVEs.

65

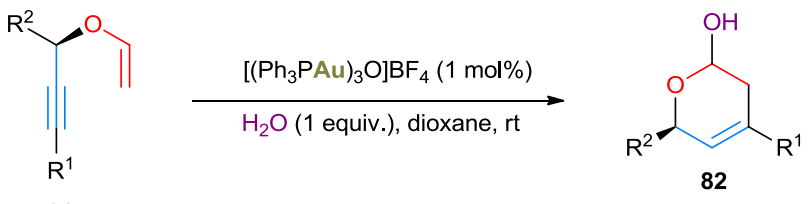

Scheme 22. Au(I)-catalysed synthesis of 2-hydroxy dihydropyrans.

The work by Toste and co-workers sparked a great amount of research dealing with the metal-catalysed propargyl Claisen 70 rearrangement. For instance, as part of a program directed to the search of novel and effective catalytic systems that selectively activate alkynes, Shi et al. studied triazole-gold catalysts in the rearrangement of PVEs bearing aromatic and alkyne substituents, 
reminiscent of the work previously described in Scheme 20. In this work, the substrates were devised so that a Schmittel cyclisation would be favoured in the course of the reaction. Therefore, PVEs $\mathbf{8 3}$ went through a propargyl Claisen 5 rearrangement - radical cyclisation cascade process to afford the tetracyclic products $\mathbf{8 4}$. Similarly, PVE 85 was converted into 86 containing a different substitution pattern (Scheme 23). ${ }^{47}$ Both transformations proceeded with good chemoselectivity under mild reaction conditions $\left(0{ }^{\circ} \mathrm{C}\right.$ to room temperature in $\mathrm{CH}_{2} \mathrm{Cl}_{2}$ as 10 the solvent).
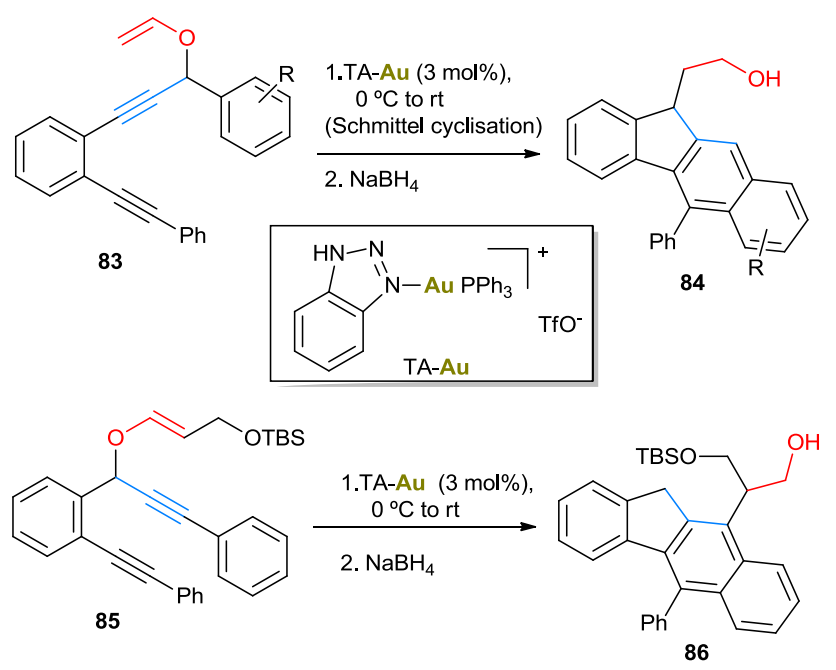

Scheme 23. Gold-catalysed propargyl Claisen rearrangement - Schmittel cyclisation.

15 The group of Nevado and co-workers envisioned a domino process in which a cyclopropyl group could participate once the propargyl Claisen rearrangement would have taken place. Hence, substrates $\mathbf{8 7}$ and $\mathbf{8 9}$ accommodating the small-size ring directly bonded to the alkyne moiety were stirred with catalytic amounts 20 of a gold catalyst at ambient temperature to deliver substituted cyclopentenes $\mathbf{8 8}$ and $\mathbf{9 0}$ in good yields and short periods of time (Scheme 24). ${ }^{48}$ The domino process therefore included a [3,3]sigmatropic rearrangement, a cyclopropyl ring opening and a cyclisation. Key to the success of the reaction was the presence of 25 a substituent $\mathrm{R}$ that would aid in the delocalization of the $\delta^{+}$ generated upon cyclopropyl ring opening.

The ease of preparation of PVEs bearing an ester substituent at the vinyl functionality ${ }^{19-22}$ in combination with metal catalysis has also been the source of inspiration for various research 30 groups, especially those of Kirsch and co-workers ${ }^{49-52}$ and Jiang and co-workers. ${ }^{53,54}$ As Scheme 25 summarises, PVEs can be converted via domino processes into furans $\mathbf{9 2}^{53,54}$ or $\mathbf{9 3},{ }^{49,57} 2 \mathrm{H}$ pyrans $\mathbf{9 5}^{50}$ or 3,6-dihydro- $2 \mathrm{H}$-pyrans $97 .{ }^{56}$ Likewise, PVEs has been transformed into pyrroles $\mathbf{9 4}^{51}$ and 1,2-dihydropyridines ${ }_{35} \mathbf{9 6}^{52,55}$ in one pot manner in the presence of an suitable base and a primary amine. Although in the majority of occasions gold complexes are used as catalysts, there have also been reports of the use of copper, silver, iron and palladium salts. Key to these transformations is the correct choice of the metal catalyst to 40 selectively activate the different species present in the reaction pathway (PVE, oxocarbenium ion and allene, Scheme 21).<smiles>[R]C=C1C(CCO)=CCC1[R]</smiles><smiles>[Mg][Mg][Mg]</smiles>

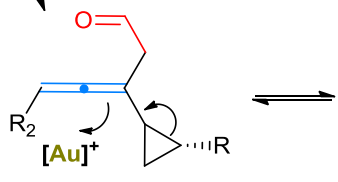<smiles>[R]C=C([Al])C(=CC[CH]C)CC=C</smiles><smiles>[R]C(C#CC1CC1[R])O/C=C/C(C)=O</smiles><smiles>[R4]C=C1C(=C(C=O)C(C)=O)CCC1[R]</smiles>

Scheme 24. Au(I)-catalysed Claisen rearrangement - cyclopropyl ring opening - cyclisation.

45 Another important aspect is that ingenious methodologies can be designed so that nucleophiles that are unreactive towards the PVE could trap one of the reaction intermediates to afford even more diversity in the product distribution (e.g., 94 and 96 ).

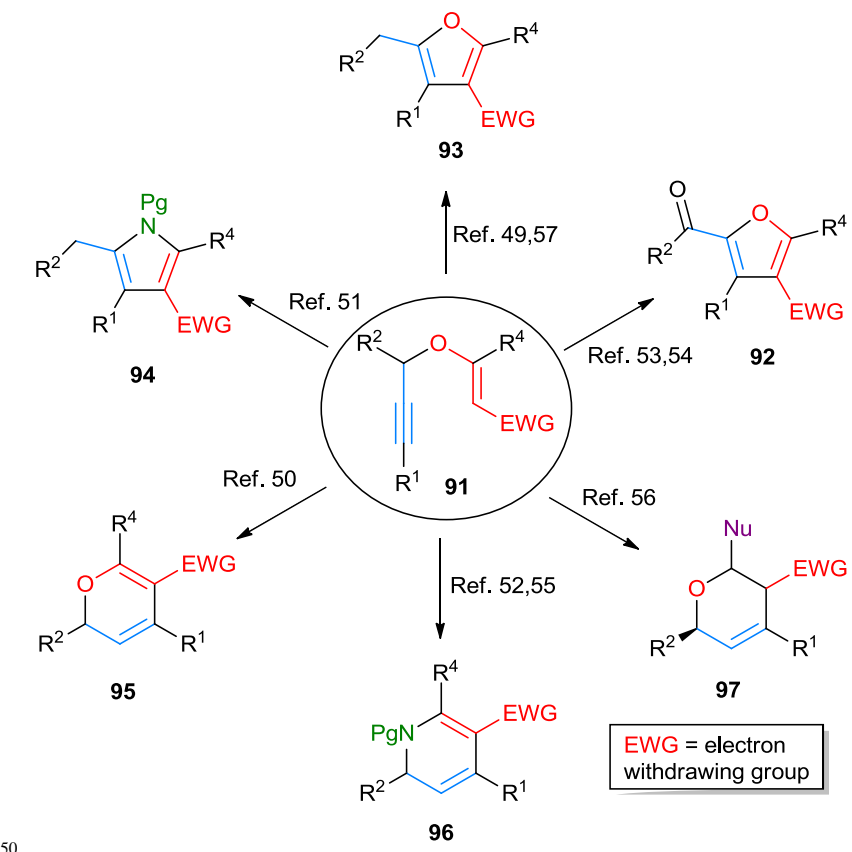

Scheme 25. Metal-catalysed transformations from PVEs.

A different scenario takes place if the electron withdrawing group of the vinyl group is located at the other carbon position. 55 The synthesis of these PVEs is not as straightforward (4 steps are required staring from propargyl alcohols) but their $[3,3]$ sigmatropic rearrangement (sometimes referred as the GosteliClaisen rearrangement) leads to new transformations that depend on the reaction conditions. Thus, Hiersemann and co-workers ${ }^{58}$ 60 have reported catalysed and uncatalysed domino molecular 
transformations from PVEs 98 (Scheme 26). Not surprisingly, in the presence of the $\mathrm{Ph}_{3} \mathrm{PAuCl} / \mathrm{AgSbF}_{6}$ system, tetrasubstituted furans 99 were obtained following the reactivity principle described in Scheme 21. On the other hand, thermal 5 rearrangement of PVEs $\mathbf{9 8}$ afforded the allenic $\alpha$-ketoester $\mathbf{1 0 0}$ if performed in 1,2-dichloroethane, or an unexpected polysubstituted cyclopentene $\mathbf{1 0 1}$ if performed in fluorinated alcohols which act as nucleophiles.<smiles>[R7]c1c(C(=O)O)oc(C)c1C</smiles>

99

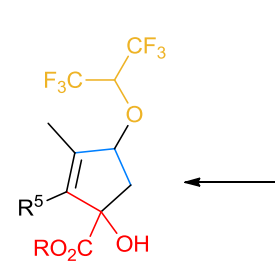

101

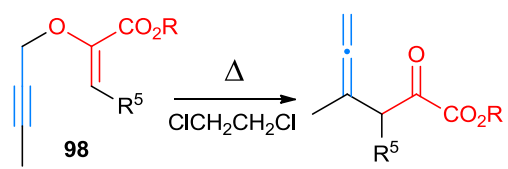

100

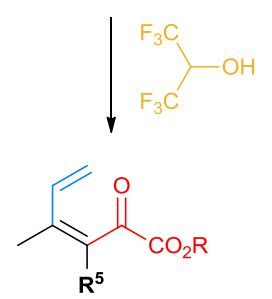

Scheme 26. Gosteli-Claisen rearrangement of propargyl vinyl ethers.

Microwave-driven domino processes. Redounding on the use of easily accessible PVEs synthesised from propargyl alcohols and 15 conjugated alkynoates, our research group has studied the metalfree, microwave-induced rearrangement of these substrates in the presence or absence of external nucleophiles with very simple and bench friendly experimental protocols. It is important to highlight that this is not a simple issue of replacing the metal 20 catalysis by microwave irradiation to obtain the same set of products, as the reactive pathway of the domino processes varies considerably. Under microwave irradiation, and in the absence of a species capable of activating the allene intermediate $\mathbf{1 0 3}$ obtained from the propargyl Claisen rearrangement of PVE 102, 25 the diene 104 becomes the key intermediate of all the domino processes shown in Schemes 27-28. The diene $\left(R^{2}=P h\right)$ was isolated when the rearrangement was carried out in the absence of an external nucleophile. On the other hand, in the presence of suitable primary amines, this diene was trapped in the form of the 30 corresponding imine which afforded the corresponding 1,2dihydropyridines $\mathbf{1 0 5}$ by a $6 \pi$-aza-electrocyclisation reaction. ${ }^{59}$ Furthermore, if the primary amine contained an appropriate leaving group (i.e. $\mathrm{MeONH}_{2}$ ), the domino process could be prolonged to include an elimination/aromatisation step leading to 35 functionalised nicotinic acid derivatives $\mathbf{1 0 6}{ }^{60}$

The presence of $O$-nucleophiles instead of $N$-nucleophiles changed the course of the reaction. If the propargyl Claisen rearrangement was carried out in an alcoholic solvent, the key dienal intermediate $\left(\mathrm{R}^{4}=\mathrm{H}\right)$ suffered a nucleophilic attack and an 40 internal [1,5]-hydrogen shift from the hemiacetal center to the terminus of the conjugated diene rendering $\beta, \gamma$-unsaturated malonates $\mathbf{1 0 7}$ with complete stereoselectivity. ${ }^{61}$ Alternatively, if<smiles>[R]C=CC([R])=C(C([R])=N[R16])C([R])=NC=CC</smiles>

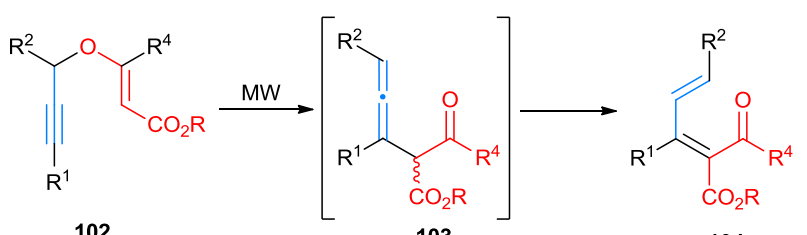

102

103

104

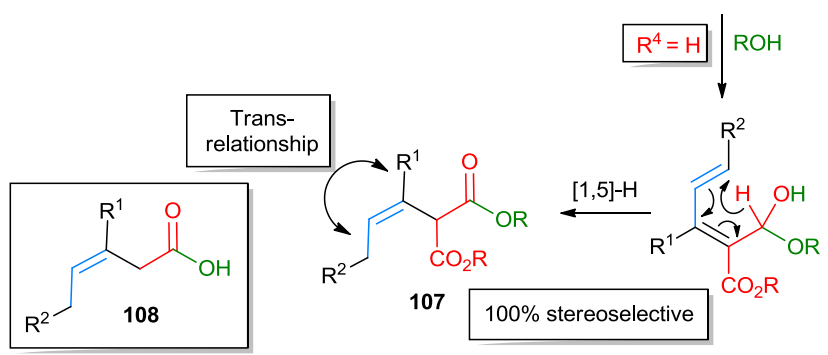

45 Scheme 27. Metal-free, microwave-induced transformations from PVEs.

$\mathrm{H}_{2} \mathrm{O}$ was used as the reaction medium, an additional decarboxylation step took place changing the chemical outcome of the reaction to afford $\beta, \gamma$-unsaturated acids (esters) 108 with 50 high stereoselectivity.

Complementarily, PVEs containing at least two hydrogens at the homopropargylic position $\left(\mathrm{R}^{2}=\mathrm{CH}_{2} \mathrm{R}^{\prime}\right)$, could be converted into multifunctionalized aromatic products 109 via a novel domino process and in the presence of molecular sieves $4 \AA$ (an ${ }_{55}$ effective methanol scavenger). ${ }^{62}$ The mechanistic proposal after the formation of the key dienal intermediate 104 includes a $4 E / 4 Z$ isomerization, a [1,5]-hydride shift, enolization, an electrocyclisation, and finally, the aromatization of the ring due to the subsequent loss of methanol (Scheme 28).

60

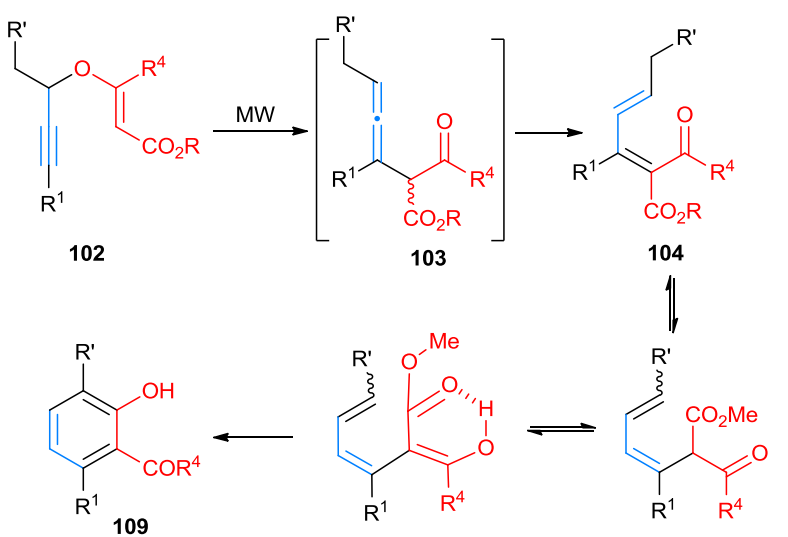

Scheme 28. Microwave-induced synthesis of salicylaldehyde derivatives.

The only strategy that our group has been able to implement 65 with the aim of taking advantage of the allenic species under metal-free conditions is the use on an additional electron 
withdrawing group in the propargylic position of the starting PVE. The role of this extra functionality is to activate the central carbon atom of the allene functionality of intermediate $\mathbf{1 1 1}$ and thus facilitate a 5-exo-dig $O$-cyclisation reaction. Therefore, 5 tertiary propargyl vinyl ethers $\mathbf{1 1 0}$ armed with an electronwithdrawing group (amide or ester) ${ }^{63}$ have been converted into trisubstituted furans 112 (Scheme 29). ${ }^{64}$

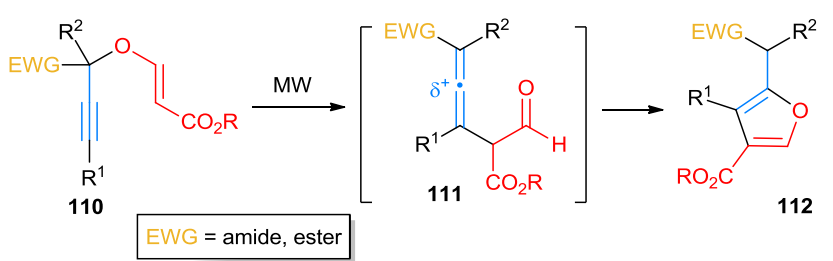

${ }_{10}$ Scheme 29. Metal-free, microwave-induced synthesis of furans.

\section{Conclusions}

The [3,3]-sigmatropic rearrangement of propargyl vinyl ethers is more than just the acetylenic version of the Claisen rearrangement. At first sight, it is a known strategy to gain access 15 to functionalized allenes, but when studied in more detailed, we find that it may be combined with other known reactivities to gain access to much more complex compounds, often, in a very elegant manner.

There are diverse methodologies that facilitate the study of the 20 propargyl Claisen rearrangement. Among them, the Johnson orthoester Claisen rearrangement of substituted propargylic alcohols is one of the most common, robust and reliable methods to synthesise valuable $\beta$-allenic esters which are later converted into a wide range of products, usually, with high levels of 25 enantiomeric excess. In this case, the PVEs are only convenient intermediates of the complete transformation because they can never be isolated under the reaction conditions required for their formation. Alternatively, isolable PVEs possessing a substituted vinyl functionality are most easily accessed from the reaction of 30 propargyl alcohols and readily available conjugated alkynoates. The availability of these PVEs along with novel metal-catalysed and microwave-induced strategies have sparked a great interest in the development of new domino processes.

It is anticipated that the future will bring the design of new 35 strategies that will combine the propargyl Claisen rearrangement with other reactivities in yet more innovating domino processes. Furthermore, new methodologies will be designed for the synthesis of propargyl vinyl ethers which will aid in the broadening of this powerful organic synthetic tool.

40

\section{Acknowledgment}

This research was supported by the Spanish Ministerio de Economía y Competitividad and the European Regional Development Fund (CTQ2011-28417-C02-02). G.M.A. and L.C. 45 thank the Spanish MEC for FPU and FPI grants, respectively.

\section{Notes and references}

${ }^{a}$ Instituto de Productos Naturales y Agrobiología, CSIC, Astrofísico Francisco Sánchez 3, 38206 La Laguna, Tenerife, Canary Islands, Spain. Fax: int-34922-260135; Tel: int-34922-256847; E-mail:

50 fgarcia@ipna.csic.es; dtejedor@ipna.csic.es

1.- L. Claisen, Chem. Ber., 1912, 45, 3157-3167.
2 A. M. M. Castro, Chem. Rev., 2004, 104, 2939-3002.

3 F. E. Ziegler, Chem. Rev., 1988, 88, 1423-1452.

4. M. Hiersemann, U. Nubbemeyer, Eds. The Claisen Rearrangement; 55 Wiley-VCH: Weinheim, Germany, 2007.

5 For an older review on intramolecular pericyclic reactions of acetylenic compounds see: A. Viola, J. J. Collins, N. Filipp, Tetrahedron, 1981, 37, 3765-3811.

6 B. S. Thyagarajan, K. K. Balasubramanian, R. B. Rao, Tetrahedron 60 Lett., 1963, 21, 1393-1398.

7. D. K. Black, S. R. Landor, J. Chem. Soc., 1965, 6784-6788.

8. S. Ma, Chem. Rev., 2005, 105, 2829-2871.

9. B. D. Sherry, F. D. Toste, J. Am. Chem. Soc., 2004, 126, $15978-$ 15979. The metal-catalysed rearrangement takes place with a deviation from a concerted mechanism. The PVE rearranges to a cyclic oxocarbenium ions which then opens to the allenic species (See Scheme 21).

10. T. Tsuno, H. Hoshino, R. Okuda, K. Sugiyama, Tetrahedron, 2001, 57, 4831-4840.

70 11. H. Zachova, S. Man, M. Necas, M. Potacek, Eur. J. Org. Chem., 2005, 2548-2557.

12. G. Saucy and R. Marbet, Helv. Chim. Acta, 1967, 50, 1158-1167.

13. C. Wang, W. Zhao, H. Li and L. Guo, Green Chem., 2009, 11, 843847 and references cited therein.

75 14. W.S. Johnson, L. Werthermann, W.R. Bartlett, T.J. Brockson, T.-T. Li, D.J. Faulkner, and M.R. Petersen, J. Am. Chem. Soc., 1970, 92 , 741-743.

15. J. K. Crandall, G. L. Tindell, J. Chem. Soc. Chem. Comm., 1970, 1411-1412.

80 16. M. C. Croudace, N. E. Schore, J. Org. Chem., 1981, 46, 5357-5363.

17. K. Nonoshita, H. Banno, K. Maruoka, H. Yamamoto, J. Am. Chem. Soc., 1990, 112, 316-322.

18. The vinylation of a terminal alkyne using this methodology has been reported to proceed in very poor yield $(5 \%)$. K. Mori, Tetrahedron, 2012, 68, 1936-1946.

19. D. Tejedor, A. Santos-Expósito, G. Méndez-Abt, C. Ruiz-Pérez, F García-Tellado, Synlett, 2009, 1223-1226.

20. J. Inanaga, Y. Baba, T. Hanamoto, Chem. Lett., 1993, 241-244.

21. S. Inuki, S. Oishi, N. Fujii, H. Ohno, Org. Lett., 2008, 10, 5239-5242.

90 Used in the total synthesis of indole alkaloids of the ergot family. Propargyl Claisen rearrangement under thermal, microwave and $\mathrm{Au}$ catalysed conditions.

22. P. de Armas, F. García-Tellado, J. J. Marrero-Tellado, D. Tejedor, M. A. Maestro, J. González-Platas, Org. Lett., 2001, 3, 1905-1908.

95 23. G. E. Veitch, E. Beckmann, B. J. Burke, A. Boyer, S. L. Maslen, S. V. Ley, Angew. Chem., Int. Ed., 2007, 46, 7629-7632.

24. T. Cao, J. Deitch, E. C. Linton, M. C. Kozlowski, Angew. Chem., Int. Ed., 2012, 51, 2448-2451.

25. V. Vaithiyanathan, K. Selvakumar, P. Shanmugam, Synlett, 2009, 1591-1596.

26. R. R. Akhmetvaleev, L. R. Imaeva, T. A. Belogaeva, M. S. Miftakhov, Russ. Chem. Bull., 1997, 46, 1963-1964.

27. B. A. Otter, S. S. Saluja, J. J. Fox, J. Org. Chem., 1972, 37, 2858 2863.

105 28. S. J. Meek, R. V. O’Brien, J. Llaveria, R. R. Schrock, A. Hoveyda, Nature, 2011, 471, 461-466.

29. P. Cao, B. Wang, X. Zhang, J. Am. Chem. Soc., 2000, 122, 64906491.

30. K. C. M. Kurtz, M. O. Frederick, R. H. Lambeth, J. A. Mulder, M. R. Tracey, R. P. Hsung, Tetrahedron, 2006, 62, 3928-3938.

31. R. A. Brawn, J. S. Panek, Org. Lett., 2007, 9, 2689-2692.

32. R. A. Brawn, J. S. Panek, Org. Lett., 2010, 12, 4624-4627 and references cited therein.

33. B. M. Trost, A. B. Pinkerton, M. Seidel, J. Am. Chem. Soc., 2001, 123, 12466-12476.

34. K. A. Parker, J. J. Petraitis, R. W. Kosley, S. L. Buchwald, J. Org. Chem., 1982, 47, 389-398.

35. J. C. Aponte, G. B. Hammond, B. Xu, J. Org. Chem., 2009, 74, 46234625.

120 36. X. Jiang, C. Fu, S. Ma, Chem. Eur. J., 2008, 14, 9656-9664.

37. B. Lu, X. Jiang, C. Fu, S. Ma, J. Org. Chem., 2009, 74, 438-441. 
38. W. Kong, J. Cui, Y. Yu, G. Chen, C. Fu, S. Ma, Org. Lett., 2009, 11, 1213-1216.

39. Y. Tang, L. Shen, B. J. Dellaria, R. P. Hsung, Tetrahedron Lett., 2008, 48, 6404-6409.

5 40. R. W. Sadfrank, A. Welch, M. Haubner, Angew. Chem., Int. Ed., 1995, 34, 2709.

41. R. W. Bates, C. J. Lim, Synlett, 2010, 866-868.

42. M. Georgy, P. Lesot, J.-M. Campagne, J. Org. Chem., 2007, 72, 3543-3549.

10 43. J. D. Ha, J. K. Cha, J. Am. Chem. Soc., 1999, 121, 10012-10020.

44. E. Okazaki, R. Okamoto, Y. Shibata, K. Noguchi, K. Tanaka, Angew. Chem., Int. Ed., 2012, 51, 6722-6727.

45. J. W. Grissom, D. Klingberg, D. Huang, B. J. Slattery, J. Org. Chem., 1997, 72, 603-626.

15 46. B. D. Sherry, L. Maus, B. N. Laforteza, F. D. Toste, J. Am. Chem. Soc., 2006, 128, 8132-8133.

47. Q. Wang, S. Aparaj, N. G. Akhmedov, J. L. Petersen, X. Shi, Org. Lett., 2012, 14, 1334-1337.

48. D. Garayalde, E. Gómez-Bengoa, X. Huang, A. Goeke, C. Nevado, J.

$20 \quad$ Am. Chem. Soc., 2010, 132, 4720-4730.

49. M. H. Suhre, M. Reif, S. F. Kirsch, Org. Lett., 2005, 7, 3925-3927.

50. H. Menz, S. F. Kirsch, Org. Lett., 2006, 8, 4795-4797.

51. J. T. Binder, S. F. Kirsch, Org. Lett., 2006, 8, 2151-2153

52. T. Harschneck, S. F. Kirsch, J. Org. Chem. 2011, 76, 2145-2156.

25 53. H. Cao, H.-F. Jiang, H.-W. Huang, J.-W. Zhao, Org. Biomol. Chem., 2011, 9, 7313-7317 and references cited there in.

54. H. Huang, H. Jiang, H. Cao, J. Zhao, D. Shi, Tetrahedron, 2012, 68, 3135-3144 and references cited there in.

55. H. Wei, Y. Wang, B. Yue, P.-F. Xu, Adv. Synth. Catal., 2010, 352, 2450-2454.

56. E. Matoušová, A. Růžička, J. Kuneš, J. Králová, M. Pour, Chem. Commun., 2011, 47, 9390-9392.

57. A. Saito, T. Konishi, Y. Hanzawa, Org. Lett., 2010, 12, 372-374. This work also describes the amino-Claisen rearrangement of $\mathrm{N}$ propargyl enaminone derivatives leading to polysubstituted pyrroles.

58. A. Gille, J. Rehbein, M. Hiersemann, Org. Lett. 2011, 13, 2122-2125.

59. D. Tejedor, G. Méndez-Abt, F. García-Tellado, Chem. Eur. J., 2010, 16, 428-431.

60. D. Tejedor, G. Méndez-Abt, F. García-Tellado, Eur. J. Org. Chem., $40 \quad 2010,6582-6587$.

61. D. Tejedor, G. Méndez-Abt, L. Cotos, F. García- Tellado, Chem. Eur. J., 2012, 18, 3468-3472.

62. D. Tejedor, G. Méndez-Abt, L. Cotos, M. A. Ramírez, F. GarcíaTellado, Chem. Eur. J., 2011, 17, 3318-3321.

4563 . For the synthesis of these platforms, see: D. Tejedor, SantosExpósito, F. García- Tellado, Chem. Eur. J., 2007, 13, 1201-1209.

64. D. Tejedor, L. Cotos, F. García- Tellado, Org. Lett., 2011, 13, 44224425. 